proposed that memory functions were disrupted not by hippocampal damage, but by damage to temporal stem white matter adjacent to the hippocampus. Damage to both the hippocampus and the amygdala was required to produce severe amnesia in monkeys and humans. A circumscribed bilateral lesion involving the entire rostro-caudal extent of the CA1 field of the hippocampus caused memory impairment in the absence of other cognitive dysfunction. By use of the high resolution MRI the hippocampal region was found to be shrunken and atrophic in 4 amnesic patients while the temporal lobe was of normal size. Memory is classified as declarative (explicit) or non-declarative (implicit). Declarative memory refers to recollection of facts and events and depends on the integrity of the medial temporal lobe. Non-declarative memory refers to a collection of skills, habits, priming, conditioning and non-associated learning, all of which are non-conscious recollections, and is independent of the medial temporal lobe. The medial temporal lobe memory system is essential for establishing long-term memory for facts and events and is needed to bind together the distributed storage sites in neocortex that represent a whole memory. As time passes after learning, memory stored in the neocortex gradually becomes independent of the medial temporal lobe structures and the role of this system in memory is only temporary. More permanent memory develops presumably as a result of slow synaptic change and in concert with normal forgetting. The process by which the burden of long-term permanent memory storage is gradually assumed by the neocortex assures that the medial temporal lobe system is always available for the acquisition of new information. (Squire LR, Zola-Morgan S. The medial temporal lobe memory system. Science Sept 20,1991; 253:1380-1385).

COMMENT: The article refers to a neuropsychological evaluation of a patient, H.M., with a profound and a selective impairment in human memory after bilateral surgical removal of the medial temporal lobe (Scoville WB, Milner B. J Neurol Neurosurg Psychiatry 1957; 20:11). A reference to Marcel Proust's novel of the mind "The Remembrance of Things Past," is made in an editorial by Hilts PJ in The New York Times Sept 24, 1991. Proust's memory of a town and gardens was triggered by the pleasures of a morsel of cake soaked in a spoonful of warm tea, a mechanism involving the amygdala.

\title{
EEG AND SPELLING DISABILITIES
}

The EEGs in 23 13-year-old Finnish-speaking boys with spelling disabilities and in 21 matched controls were studied in the Departments of Child Neurology, Paediatrics, Clinical Neurophysiology and Psychology, University of Helsinki, Finland. The visual assessment of the records showed an abnormal EEG in $48 \%$ of the index group and in $25 \%$ of controls. The abnormalities included a general excessive slow activity, temporal slow wave activity and non-paroxysmal slowing. The frequency of paroxysmal activity did not differ significantly in the two groups; $4 \%$ in the index group and $9.5 \%$ in controls. A neurotic disposition measured by the Tennessee Self-concept scale and clinical subscale was more frequent in the index group than controls and reading was slightly impaired. Arithmetic skills were comparable in the 
two groups. In covariance analysis the qEEG parameter differences between the index group and controls were partly explained by the neurotic traits and emotional tension characteristic of the children with spelling difficulties. (Byring RF et al. EEG in children with spelling disabilities. Electroenceph clin Neurophysiol Oct $1991 ;$ 79:247-255).

COMMENT. Poor rhythmicity and low voltage of the background rhythm has been found in the EEG of children with learning disabilities, and visual EEG analysis has shown a large variety of EEG abnormalities associated with dyslexia (Hughes JR. In: Benton AL and Pearl D (Eds), Dyslexia - An Appraisal of Current Knowledge, Oxford University Press, New York. 1978:205-249. The present authors stress that psychopathology may be a confounding factor in the interpretation of EEG abnormalities in association with spelling disabilities and dyslexia.

\section{ETIOLOGY OF ATTENTION DEFICIT DISORDERS}

Familial-genetic factors in the etiology of attention deficit disorder $(\mathrm{ADDH})$ were studied in 145 children who met the DSM-III criteria at the Neuropediatrics Unit, Shaare Zedek Medical Center, Jerusalem, Israel. Boys outnumbered girls by $3: 1$. $30 \%$ of ADDH children had siblings with LD, compared to $6.7 \%$ in 30 normal children. $34 \%$ of ADDH children were of North African descent which comprised only $12 \%$ of the population in Jerusalem. ADDH was correlated with delayed language development and intrauterine growth retardation. No correlation was found between ADDH and numerous pre- and peri-natal factors, IQ, parental age, years of education, profession, and language spoken at home (Gross-Tsur V et al. Attention deficit disorder: association with familial-genetic factors. Ped Neurol July/Aug 1991; $\underline{7}: 258-261$ ).

COMMENT. A familial-genetic factor has been implicated in the etiology of ADHD in previous studies and the present report supports this finding. The familial-genetic factor was expressed by the male preponderance, the increased frequency of learning disabilities in siblings and an ethnic propensity. A delay in language development should alert the pediatrician to the possible development of ADDH and the need for early intervention programs. The benefits of early educational programs for parents concerning methylphenidate in the treatment of ADHD are demonstrated in a report from The Children's Hospital of Michigan, Detroit (Liu C et al. Social acceptability of methylphenidate and behavior modification for treating attention deficit

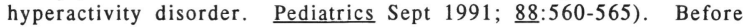
educational intervention families rated behavior modification as the most acceptable and methylphenidate as the least acceptable method of management. After 3-1/2 months experience with interventions for their children there was a significant increase in acceptability of methylphenidate related to the parental education about ADHD. 